\title{
Editorial: Enhanced Recovery after Surgery Pathways: Improving the Perioperative Experience and Outcomes of Cancer Surgery Patients
}

\author{
Timothy M. Pawlik, MD, MPH, MTS, PhD, FACS, FRACS (Hon.) \\ Department of Surgery, The Urban Meyer III and Shelley Meyer Chair for Cancer Research, The Ohio State University, \\ Wexner Medical Center, Columbus
}

This issue of Annals of Surgical Oncology focuses on Enhanced Recovery After Surgery $\left(\mathrm{ERAS}^{\circledR}\right)$ for patients undergoing cancer operations. ${ }^{1-10}$ The term "ERAS" was invented by a group of academic surgeons who started the ERAS study group in London in 2001. ${ }^{11}$ Initially born out of "fast-tracking" patients following elective colon resection, ${ }^{12}$ the concept quickly pivoted to focus more on overall patient recovery rather than simply expeditious postsurgical discharge. In particular, enhanced recovery seeks to create a uniform experience for the surgical patient as they journey through their episode of care. As such, elements of enhanced recovery necessarily involve care coordination among surgeons, anesthetists, nurses, dieticians, physical therapists, as well as case managers. The ultimate goal of ERAS is to create a coordinated and evidenced-based pathway of care that will support the patient's recovery and help secure an optimal patient-centric outcome. Key physiologic cornerstones of any ERAS pathway involve reduction of metabolic stress, as well as maintaining fluid homeostasis. Surgery typically induces a catabolic state with concomitant insulin resistance that can disturb glucose and glycogen homeostasis, reduce muscle function, as well as perturb other metabolic pathways involved in recovery. ${ }^{13-15}$ Over the last decade, there has been an increased realization that the nil per os preoperative state can induce a preoperative diabetic-like state and adversely impact

(C) Society of Surgical Oncology 2021

First Received: 19 June 2021

Accepted: 21 June 2021;

Published Online: 30 June 2021

T. M. Pawlik, MD, MPH, MTS, PhD, FACS, FRACS (Hon.)

e-mail: tim.pawlik@osumc.edu insulin and glucose homeostasis, which may lead to worse postoperative outcomes. ${ }^{16}$ In turn, many ERAS protocols have incorporated perioperative nutrition to avoid prolonged starvation, as well as carbohydrate intake to induce insulin sensitivity before surgery. ${ }^{17}$ Another key element of enhanced recovery focuses on fluid homeostasis. While liberal use of fluids for surgical patients has been a longstanding tradition, more recent data suggest that excessive crystalloid use can delay return of bowel function, increase risk of pulmonary complications, as well as increase the risk of other major complications. ${ }^{18,19}$ Most ERAS pathways therefore encourage attention to goal-based fluid management. In addition to carbohydrate and fluid management, recovery pathways incorporate a wide range of other elements (e.g., rehabilitation, normothermia, early initiation of per os intake postoperatively, early ambulation, minimization of opioid utilization, etc.). In aggregate, these components of ERAS-based pathways help attenuate the inflammatory stressors associated with surgery and lead to improvements in perioperative outcomes. ${ }^{20}$

To date, most published data have validated the benefits of enhanced recovery pathways. In particular, several randomized trials and metaanalyses have demonstrated a consistent advantage of ERAS pathways to reduce length of stay, as well as decrease the incidence of complications following major surgical procedures. ${ }^{21-24}$ In fact, ERAS protocols have repeatedly been noted to lead to reduction in length of hospital stay and improved surgical outcomes. ERAS protocols also more actively engage patients in education about the surgical procedure itself, as well as help manage expectations relative to the anticipated postoperative course. In addition, financial models, based on published data and experience, demonstrate that ERAS programs can lead to net financial savings. ${ }^{25,26}$ Given the 
documented benefits, ERAS has been widely adopted and implemented for a wide range of surgical procedures and disease indications.

I am grateful to have organized this important issue of Annals of Surgical Oncology in my role as Deputy Editor. The issue covers a number of important topics relevant to enhanced recovery for cancer patients. In particular, an impressive team of experts detailed the latest updates on enhanced recovery for a wide range of oncologic surgical procedures including, among others, head and neck, esophageal, breast, liver, pancreas, and peritoneal malignancies, as well as colon cancer. In reading these articles, ${ }^{1-10}$ one will note common themes, yet also appreciate the various nuances and differences inherent in ERAS protocols for different surgical procedures. These articles are designed to provide practical guidelines to practicing surgical oncologists to inform perioperative care in their own clinical settings. Our hope is that these articles provide concrete, evidence-based guides to generate increased interest, enthusiasm, and participation in enhanced recovery pathways. Any enhanced recovery pathway is only as successful as the providers across the continuum of care who actively participate in its implementation.

I owe a great debt of gratitude to the wonderful group of authors who contributed to this issue of Annals of Surgical Oncology. This team of authors has done a masterful job of highlighting the important and relevant aspects of enhanced recovering in the care of cancer patients. I am convinced that this issue of Annals of Surgical Oncology will serve faculty and trainees well in understanding how enhanced recovery and ERAS protocols can improve the care of cancer patients.

\section{REFERENCES}

1. Saraswathula A, Gourin CG, Vosler PS. Guide to enhanced recovery for cancer patients undergoing surgery: head and neck cancer. Ann Surg Oncol. 2021. https://doi.org/10.1245/s10434021-10029-7.

2. Shah US, Holder-Murray J, McCoy KL. Guide to enhanced recovery for cancer patients undergoing thyroidectomy. Ann Surg Oncol. 2021. https://doi.org/10.1245/s10434-021-10100-3.

3. Halliday L, Moorthy K. Guide to enhanced recovery for cancer patients undergoing surgery: ERAS and oesophagectomy. Ann Surg Oncol. 2021. https://doi.org/10.1245/s10434-021-10384-5.

4. Heiden BT, Semenkovich TR, Kozower BD. Guide to enhanced recovery for cancer patients undergoing surgery. Ann Surg Oncol. 2021. https://doi.org/10.1245/s10434-021-09882-3.

5. Chagpar AB. Guide to enhanced recovery for cancer patients undergoing breast surgery and reconstruction. Ann Surg Oncol. 2021. https://doi.org/10.1245/s10434-021-09796-0.

6. $\mathrm{Hu} \mathrm{Y}, \mathrm{Hsu}$ AW, Strong VE. Enhanced recovery after major gastrectomy for cancer. Ann Surg Oncol. 2021. https://doi.org/10. 1245/s10434-021-09906-y.

7. Dhiman A, Fenton E, Whitridge J, et al. Guide to enhanced recovery for cancer patients undergoing surgery: ERAS for patients undergoing cytoreductive surgery with or without HIPEC. Ann Surg Oncol. 2021. https://doi.org/10.1245/s10434021-09973-1.

8. Hamad A, Pawlik TM, Ejaz A. Guide to enhanced recovery for cancer patients undergoing surgery: pancreaticoduodenectomy. Ann Surg Oncol. 2021. https://doi.org/10.1245/s10434-021-0971 7-1.

9. Newhook TE, Aloia TA. Guide to enhanced recovery for cancer patients undergoing liver surgery. Ann Surg Oncol. 2021. https://d oi.org/10.1245/s10434-021-09954-4.

10. Squeo GC, Kane WJ, Hedrick TL. Guide to enhanced recovery for cancer patients undergoing surgery: ERP and colorectal cancer surgery. Ann Surg Oncol. 2021. https://doi.org/10.1245/ s10434-021-09802-5.

11. Ljungqvist O. ERAS-enhanced recovery after surgery. $J$ Parenteral Enteral Nutr. 2014;38(5):559-66.

12. Fearon KC, Ljungqvist O, Meyenfeldt M, et al. Enhanced Recovery after Surgery: a consensus review of clinical care for patients undergoing colonic resection. Clin Nutr. 2005;24(3):466-77.

13. Ljungqvist $O$. Insulin resistance and enhanced recovery after surgery: Jonathan E. Rhoads Lecture 2011. J Parenter Enteral Nutr. 2012;3(4):389-98.

14. Henriksen MG, Hessov I, Dela F, Vind Hansen H, Haraldsted V, et al. Effects of preoperative oral carbohydrates and peptides on postoperative endocrine response, mobilization, nutrition and muscle function in abdominal surgery. Acta Anaesthesiol Scand. 2003;47(2):191-9.

15. Jackson RS, Amdur RL, White JC, Macsata RA. Hyperglycemia is associated with increased risk of morbidity and mortality after colectomy for cancer. J Am Coll Surg. 2012;214(1):68-80.

16. Maessen JM, Hoff C, Jottard K, et al. To eat or not to eat: facilitating early oral intake after elective colonic surgery in the Netherlands. Clin Nutr. 2009;28(1):29-33.

17. Ljungqvist $\mathrm{O}$. Modulating postoperative insulin resistance by preoperative carbohydrate loading. Best Pract Res Clin Anaesthesiol. 2009;23:401-9.

18. Doherty M, Buggy DJ. Intraoperative fluids: how much is too much? Br J Anaesth. 2012;109(1):69-79.

19. Lobo DN, Bostock KA, Neal KR, Perkins AC, Rowlands BJ, Allison SP. Effect of salt and water balance on recovery of gastrointestinal function after elective colonic resection: a randomised controlled trial. Lancet. 2002;359(9320):1812-8.

20. Page AJ, Ejaz A, Spolverato G, Zavadsky T, Grant MC, Galante DJ, et al. Enhanced Recovery after Surgery protocols for open hepatectomy - physiology, immunomodulation, and implementation. J Gastroint Surg. 2015;19:387-99.

21. Anderson AD, McNaught CE, MacFie J, Tring I, Barker P, Mitchell CJ. Randomized clinical trial of multimodal optimization and standard perioperative surgical care. $\mathrm{Br} J$ Surg. 2003;90:1497-504.

22. Delaney CP, Zutshi M, Senagore AJ, Remzi FH, Hammel J, Fazio VW. Prospective, randomized, controlled trial between a pathway of controlled rehabilitation with early ambulation and diet and traditional postoperative care after laparotomy and intestinal resection. Dis Colon Rectum. 2003;46:851-9.

23. Gatt M, Anderson AD, Reddy BS, Hayward-Sampson P, Tring IC, MacFie J. Randomized clinical trial of multimodal optimization of surgical care in patients undergoing major colonic resection. Br J Surg. 2005;92:1354-62.

24. Lv L, Shao YF, Zhou YB. The enhanced recover after surgery (ERAS) pathway for patients undergoing colorectal surgery: an update of meta-analysis of randomized controlled trials. Int $J$ Colorectal Dis. 2012;27:1549-54.

25. Stone AB, Grant MC, Roda CP, Hobson D, Pawlik TM, Wu CL, et al. Implementation costs of an enhanced recovery after surgery 
program in the United States: a financial model and sensitivity analysis based on experiences at a quaternary academic medical center. J Am Coll Surg. 2016;222(3):219-25.

26. Page AJ, Gani F, Crowley FT, Lee KHK, Grant MC, Zavabdsky TL, et al. Patient outcomes and provider perceptions following implementation of a standardized perioperative care pathway for open liver resection. Br J Surg. 2016;103(5):564-71.
Publisher's Note Springer Nature remains neutral with regard to jurisdictional claims in published maps and institutional affiliations. 